\title{
ANÁLISE DOS FATORES QUE CONTRIBUEM PARA O BAIXO ÍNDICE DE COMPARECIMENTO NA HABILITAÇÃO PARA O CURSO DE ENGENHARIA CIVIL EM UMA UNIVERSIDADE NO INTERIOR DA AMAZÔNIA
}

Fabiano Hector Lira Muller-fabiano.muller@ufopa.edu.br

Universidade Federal do Oeste do Pará, Campus de Itaituba, Curso de Engenharia Civil* Rua Universitária, S/N, Bairro Maria Madalena*

68183-300 - Itaituba - Pará*

Valquíria Santana da Silva - valquiriasantana2002@gmail.com* Universidade Federal do Oeste do Pará, Campus de Itaituba, Curso de Engenharia Civil* Rua Universitária, S/N, Bairro Maria Madalena*

68183-300 - Itaituba - Pará*

Ronne Clayton de Castro Gonçalves - ronne.goncalves@ufopa.edu.br

Universidade Federal do Oeste do Pará, Campus de Itaituba, Curso de Engenharia Civil* Rua Universitária, S/N, Bairro Maria Madalena *

68183-300 - Itaituba - Pará*

Luamim Sales Tapajós - luamim.tapajos@ufopa.edu.br*

Universidade Federal do Oeste do Pará, Campus de Itaituba, Curso de Engenharia Civil* Rua Universitária, S/N, Bairro Maria Madalena *

68183-300 - Itaituba - Pará*

Resumo: Este estudo procura traçar um perfil e verificar o motivo da não realização da matrícula por parte de alguns candidatos aprovados no curso de bacharelado em engenharia civil da Universidade Federal do Oeste do Pará - Campus Itaituba e contribuir como fonte de dados para criação de ações voltadas à minimização do número de vagas não aproveitadas, antes mesmo do início das aulas. Caracteriza-se como uma pesquisa quantitativa e descritiva e para a coleta dos dados foi encaminhado um questionário on-line aos candidatos aprovados, mas que não realizaram a matrícula no curso. Concluiu-se que os candidatos são em sua maioria do gênero masculino, na faixa etária entre 18 e 23 anos, oriundos de escola pública e que são estudantes ou estão desempregados. Constatou-se também que o fator geográfico, quando considerado isoladamente, não é o principal fator motivador para a não realização das matrículas, mas quando associado a outro fator, como a aprovação em outra instituição pública, esse acesso mais difícil até a cidade de Itaituba-PA, faz com que se priorize instituições com melhor localização geográfica. O fator geográfico ainda influenciou para que houvesse desistência dos candidatos em função do tempo para se chegar ao município para realizar sua matrícula. Verificou-se, também, que existe uma desatenção por parte de alguns candidatos que não atentam para as regras previstas em edital e nem providenciam a documentação necessária para a habilitação no curso com a devida antecedência.

Palavras-chave: Matrícula. Engenharia Civil. Ufopa. Campus Itaituba. 


\section{INTRODUÇÃO}

Ao finalizar o ensino básico, o jovem dialoga com o processo de escolha do curso de graduação que estudará, essa etapa pode ser decisiva para os caminhos futuros a serem seguidos. Essa decisão, geralmente, é pensada e leva em consideração algumas opções que se colocam como prioritárias e outras que foram descartadas durante esse processo. Essa definição leva em consideração a vontade da família, ingresso no mercado de trabalho, ambições pessoais, condições sociais, educacionais e geográficas.

O recente aumento do número de Instituições Federais de Ensino Superior possibilitou um acesso mais facilitado a cursos de graduação. Os processos de seleção tornaram-se mais abrangentes e modificaram radicalmente o perfil da recente geração de discentes dos cursos de graduação das universidades federais. O processo unificado de ingresso via Enem/Sisu e a reserva de vagas para estudantes por meio de cotas influenciam diretamente neste perfil discente.

De uma maneira geral, as instituições estão mais preocupadas em atrair novos alunos, em vez de tentar reter os já existentes, estruturando programas de permanência e de combate à evasão (SILVA FILHO et al, 2007; OLIVIERA et al., 2013). Muitos são os estudos relacionados aos motivos que levam os alunos a abandonarem os bancos universitários, porém pouco se menciona sobre os motivos que levaram os candidatos a uma vaga nos cursos de graduação a optar por um curso em detrimento a outro.

A observação de um fato ocorrido no curso de bacharelado em Engenharia Civil ofertado pelo Campus de Itaituba da Universidade Federal do Oeste do Pará (Ufopa) motivou este estudo. Mesmo sendo um dos cursos mais concorridos da instituição, não conseguiu completar o número total de vagas ofertadas no Processo Seletivo Regular Unificado da instituição. Assim, essa pesquisa objetiva verificar o motivo da não realização da matrícula no curso de engenharia civil e traçar um perfil desses candidatos que foram aprovados e que não compareceram para a realização da matrícula, e contribuir como fonte de dados para criação de ações voltadas à minimização desta problemática.

\section{REVISÃO BIBLIOGRÁFICA}

\subsection{A expansão do Ensino Superior no país}

A escolaridade é uma varável que tende a interferir diretamente nas chances de os indivíduos conseguirem uma melhor colocação no mercado de trabalho. Historicamente havia mais prestígio em instituições públicas, de difícil acesso, frente a instituições privadas, onde o acesso era menos concorrido (SALATA, 2018). A diminuição da procura pelo ensino superior na década de 80, influenciado pela instabilidade econômica, e a lógica da demanda e da oferta incidiu na expansão do ensino privado frente ao público, mostrando ineficiências no planejamento governamental para o ensino superior (NEVES e MARTINS, 2016; PEREIRA e SILVA, 2010).

A presença sempre crescente do ensino privado, com a oferta de vagas com ênfase nas carreiras e em cursos de menor custo de implantação (ciências humanas e ciências sociais aplicadas) aliado ao fato de que a maioria das IES públicas tem a oferta dos cursos diurnos, enquanto nas IES privadas possibilitam que sejam oferecidos no turno da noite (NUNES, 2007; NEVES e MARTINS, 2016), dificultam a permanência do jovem que precisa trabalhar para se manter financeiramente em uma IES pública.

Em atenção a Lei ${ }^{\circ} 10.172$, de janeiro de 2001, que aprova o Plano Nacional de Educação, houve uma expansão da Rede Federal de Educação Superior no Brasil, a qual teve 
início com a interiorização/regionalização dos Campi das universidades federais através do Programa de Apoio a Planos de Reestruturação e Expansão das Universidades Federais (Reuni) que foi instituído pelo Decreto n. 6.096, de 24 de abril de 2007, e é uma das ações que integraram o Plano de Desenvolvimento da Educação (PDE) (COCCO et al., 2014; SALATA, 2018). "Essa expansão ampliou o acesso ao Ensino Superior público e gratuito no Brasil, bem como contribuiu para a regionalização e interiorização da oferta de vagas em todo o país" (COCCO et al., 2014, p. 01).

Essa ampliação possibilitou um maior acesso e inclusão social no ensino superior com as políticas de ações afirmativas e adoção do sistema de cotas que passou a ser adotado por algumas poucas universidades no início do século XXI, mas só foi impulsionado com a sanção da Lei n. 12.711 de agosto de 2012, que obrigava as instituições federais a, gradualmente, no prazo de quatro anos, garantir 50\% das matrículas a estudantes oriundos do ensino médio público, mesclando também critérios de renda e raciais (SALATA, 2018).

Salata (2018, p. 221-222) ao discorrer sobre o acesso e as desigualdades sociais que influenciam nas condições para se manter no ensino superior, informa que "a aspiração aos níveis mais avançados de educação é menos frequente nas classes baixas, isso não se deve a uma menor valorização da educação entre estas, mas sim à maior distância - e maiores custos - que seus membros teriam que percorrer para alcançá-la”, ou seja, as desigualdades sociais latentes são fatores limitadores na escolha da formação acadêmica.

Considerando a transformação recente da estrutura produtiva e de crescimento econômico, o Brasil passou a demandar perfis profissionais mais técnicos e com formação nas áreas das engenharias. "Um dos fatos relacionados ao aumento do número de ingressantes nos cursos de Engenharia no país, (...), se refere ao grande alcance de programas do governo federal, tais como FIES e o ProUni" (ALVES e MANTONAVI, 2016, p. 28) mostrando a importância do ensino superior público.

\subsection{A interiorização do ensino da Engenharia Civil}

O sistema universitário brasileiro cresceu de forma concentrada, sobretudo em capitais e grandes centros urbanos. Influenciado diretamente pelo aquecimento do mercado da construção civil, os cursos públicos e privados de engenharia ganharam novo impulso. A criação de postos de trabalho na área, aliado a possibilidade de bons salários que são oferecidos, motiva a procura por cursos de graduação nesta área.

Em 2019 foram publicadas as novas Diretrizes Curriculares Nacionais (DCNs) dos Cursos de graduação em Engenharias que, diferentemente da versão anterior do ano de 2002, trouxe conceitos atuais como a formação baseada por competências, o foco na prática, a aprendizagem ativa e uma maior flexibilidade na constituição do currículo. Entre as habilidades e competências esperadas estão visão holística, atuação inovadora e empreendedora, além da criatividade na hora de resolver problemas da área (RECKZIEGEL, 2019).

Quando se fala na nova geração de engenheiros, espera-se profissionais mais completos, ou seja, com capacidades técnicas e mais aptidões humanísticas. Esse é o desafio que as Instituições de Ensino Superior, com cursos de Engenharia, enfrentam para se adequar. Não basta somente atrair o aluno, é preciso que este envolva-se com o meio, que entenda a sociedade e seu contexto dinâmico de mudanças, e que não deixe de lado a competência profissional que o mercado de trabalho exige.

Um desses novos cursos de engenharia que surgiram no contexto de expansão do ensino superior no Brasil, é o Bacharelado em Engenharia Civil ofertado pela Universidade Federal do 
Oeste do Pará - Ufopa, Campus Itaituba. A Ufopa foi criada pela Lei $\mathrm{n}^{\mathrm{o}} 12.085$, de 5 de novembro de 2009, sendo a primeira Instituição Federal de Ensino Superior com Sede no interior de um Estado da Amazônia brasileira. Sua Sede fica no município de Santarém e tem Campi nas cidades de Alenquer, Itaituba, Juruti, Monte Alegre, Óbidos e Oriximiná. Sua criação se deu a partir da política que instalou o Programa de Expansão das Universidades Federais do Programa de Apoio aos Planos de Reestruturação e Expansão das Universidades Federais (Reuni) e do acordo de cooperação técnica firmado entre o Ministério da Educação (MEC) e a Universidade Federal do Pará (UFPA) com o objetivo de ampliar o ensino superior na região amazônica (MULLER, 2019; UFOPA, 2020).

Os cursos de graduação ofertados pela UFOPA são estruturados em conformidade com as diretrizes curriculares nacionais estabelecidas pelo Conselho Nacional de Educação e com as normativas institucionais em diferentes áreas do conhecimento, vinculados a Institutos Temáticos e aos Campi Regionais. Com relação à Graduação, o acesso é feito via Exame Nacional do Ensino Médio (Enem), mobilidade externa e processos seletivos especiais (indígena e quilombola) (MULLER, 2019).

A estrutura acadêmica da Ufopa é focada na interdisciplinaridade, nas potencialidades regionais, e o Campus da Universidade na cidade de Itaituba apresenta potencial (hidrelétricas, ferrovias, portos de exportação, entre outros) para o desenvolvimento segmentado na sustentabilidade, na infraestrutura e na logística portuária, tendo em vista o desenvolvimento, com sustentabilidade, da região e os iminentes empreendimentos (UFOPA, 2020).

\section{METODOLOGIA}

Nesta seção estão elencados os procedimentos metodológicos que nortearam a pesquisa. Para Andrade (2018, p.109) a “[...] pesquisa é o conjunto de procedimentos sistemáticos, baseado no raciocínio lógico, que tem por objetivo encontrar soluções para problemas propostos, mediante a utilização de métodos científicos". Para que a pesquisa atinja o seu objetivo, faz se necessário a utilização de ferramentas metodológicas escolhidos pelo autor para obter os resultados desejados.

Esta pesquisa foi realizada com os candidatos que se inscreveram via Exame Nacional do Ensino Médio - ENEM e que foram aprovados em primeira ou na segunda chamada no Processo Seletivo Regular unificado (PSR), para o curso de bacharelado em engenharia civil na Ufopa Campus Itaituba, mas que não realizaram a matrícula no período determinado pelo edital, tendo como objetivo traçar um perfil desses candidatos e verificar o motivo da não realização da matricula no curso.

Com relação à abordagem, este estudo caracteriza-se como quantitativo, que para Marconi e Lakatos (2018, p. 296) "se volta para descrição, previsão e explicação, bem como para dados mensuráveis e observáveis", os quais foram organizados em gráficos e tabelas para melhor expor as informações e possibilitou uma análise mais detalhada das respostas obtidas. Do ponto de vista dos objetivos da pesquisa, esta pode ser classificada como descritiva, que para Andrade (2018, p. 112) é aquela em que "os fatos são observados, registrados, analisados, classificados e interpretados sem que o pesquisador interfira neles", possibilitando assim um melhor entendimento das informações coletadas.

Para realizar a coleta de dados, a coordenação acadêmica do Campus de Itaituba enviou um e-mail com o link de um questionário on-line aos 103 (cento e três) candidatos aprovados e que não realizaram sua matrícula junto à Instituição. Após uma semana, em função do retorno não ter sido o desejado, o mesmo link do questionário foi enviado para os números pessoais dos candidatos via aplicativo de mensagens instantâneas, obtendo-se assim um retorno mais 
satisfatório. O questionário ficou disponível, para resposta pelo público alvo, de 01 a 31 de maio de 2020.

Segundo Flick (2013, p. 167-168) as pesquisas utilizando questionário on-line têm várias vantagens, entre elas:

\footnotetext{
Baixo custo: como você não tem que imprimir seus questionários, pode economizar dinheiro [...]. Os questionários que você recebe de volta já estão inseridos e são mais facilmente transferidos para o software estatístico.

Tempo: O questionário on-line retorna mais rapidamente do que os enviados pelo correio.

Facilidade de uso: Os questionários on-line são mais fáceis de formatar e mais fáceis de navegar para o participante.

Ausência de restrições espaciais: Você pode alcançar pessoas em longas distâncias sem esperar que os questionários cheguem ao seu destino.

Índice de resposta: $\mathrm{O}$ número de perguntas não respondidas na maioria dos casos é menor nas pesquisas de levantamento on-line.
}

Este instrumento de pesquisa possibilitou alcançar candidatos que foram aprovados em diversas cidades do país, obtendo um alto índice de respostas em um tempo reduzido. As informações de contato destes candidatos foram solicitadas junto ao Centro de Tecnologia da Informação - CTIC da Ufopa Sede, pela coordenação acadêmica da Ufopa - Campus Itaituba.

\section{RESULTADOS E DISCUSSÕES}

Com os dados dos candidatos aprovados e que não realizaram a matrícula no PSR 2020 para o curso de Bacharelado em Engenharia Civil ofertado no Campus de Itaituba, a primeira informação verificada foi referente a cidade de domicílio deste candidato, com o intuito de verificar quantos são do município onde é ofertado o curso de engenharia civil. Descobriu-se que $40,7 \%$ dos candidatos residem no município de Itaituba-PA e que 59,3\% são de diversas outras cidades do Brasil, o que mostra que a procura pelo curso é expressiva e atrai a atenção de candidatos de outras regiões do país. Considerando os dados expostos, percebeu-se que maior parte dos alunos que não fizeram a matrícula eram de outras localidades, apontando para a ideia de que existe uma preferência por se estudar em localidades onde se tem vínculos familiares.

Dos 103 (cento e três) candidatos que poderiam ter respondido ao questionário on-line, obteve-se retorno de 61 (sessenta e um), o que representa 59,2\% do total, um percentual bem representativo e que possibilita maior robustez na apresentação e análise dos dados. Com relação ao perfil destes candidatos, descobriu-se que 59\% são do gênero masculino, enquanto $41 \%$ são do gênero feminino. Sob uma ótica social, considerando historicamente, a engenharia civil é vista como uma profissão que traz a ideia de um ambiente voltado ao público masculino.

A Figura 1 mostra o percentual de alunos oriundos de escolas públicas e particulares. Entre os candidatos que responderam ao questionário, $85,2 \%$ são oriundos de escola pública e apenas $14,8 \%$ vieram de escolas privadas. Essa informação ratifica os dados de uma pesquisa da Associação Nacional dos Dirigentes das Instituições Federais de Ensino Superior (Andifes), que detalha o perfil de alunos das universidades federais no País, que mostra que " $64,7 \%$ dos jovens provêm de escolas da rede pública" (ANDIFES, 2018). Esse indicador pode ajudar a instituição a traçar políticas e estratégias para facilitar o ingresso e permanência dos alunos da Ufopa. 
Figura 1 - Percentual de alunos oriundos da escola pública e privada

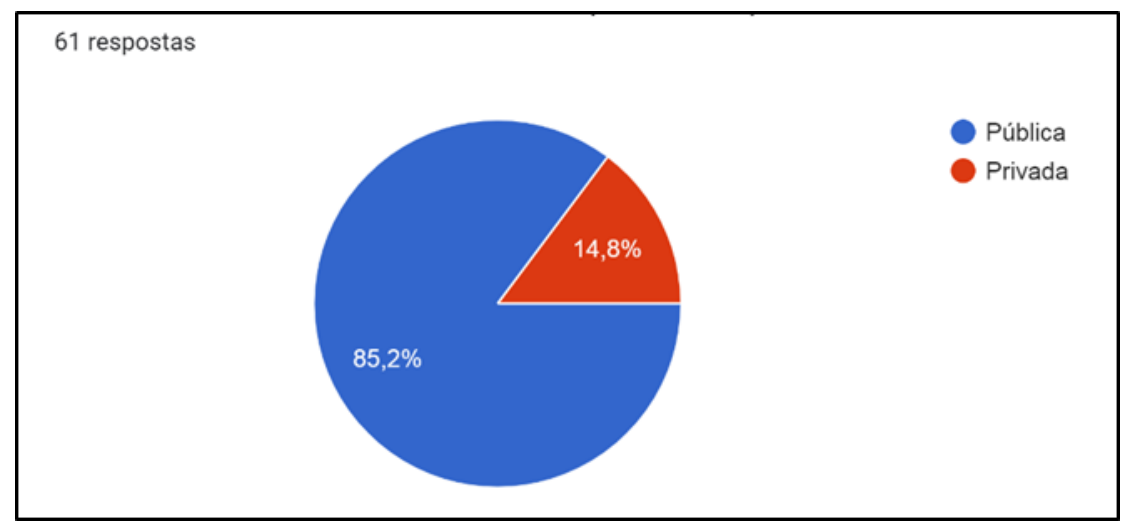

Com relação à faixa etária a pesquisa revelou que $27,9 \%$ dos candidatos aprovados tem "até 18 anos" e que 52,5\% estão "entre 18 e 23 anos" mostrando que a maior parte dos pesquisados está em busca de uma colocação do mercado de trabalho e viu no bacharelado em engenharia civil uma possibilidade. Outra análise que pode ser feita, considerando que o curso é de oferta integral, é da impossibilidade de os candidatos se custearem até o término da graduação, ou seja, a oferta integral do curso dificulta a possibilita de os candidatos terem empregos para se manter enquanto estudam.

A pesquisa mostrou também que $11,5 \%$ está na faixa etária "entre 24 e 30 anos", que 4,9\% estão "entre 31 e 40 anos" e que somente 3,3\% estão na faixa "mais de 41 anos", ou seja, a maior parte dos candidatos possuem menos de 24 anos de idade. Essa informação está alinhada com os dados de outro indicador verificado, que aponta que $78,7 \%$ dos pesquisados é "estudante ou desempregado", ou seja, a grande maioria ainda não possui uma renda. Isso reforça a ideia de dificuldade de se manter financeiramente enquanto estudam. Os dados também revelaram que 8,2\% são "trabalhadores autônomos", que 8,2\% são "trabalhadores assalariados" e que $4,9 \%$ são "servidores públicos".

Outro indicador verificado diz relação à formação de nível superior, e as respostas mostram que $88,5 \%$ "não possui formação em nível superior", enquanto $11,5 \%$ "possui alguma formação em nível superior" e busca no curso de bacharelado em engenharia civil uma segunda graduação. Isso indica que as ações da UFOPA devem estar voltadas, principalmente, para os alunos que buscam sua primeira graduação.

A Figura 2 mostra o resultado sobre o questionamento quanto ao conhecimento, por parte do candidato aprovado, da sua aprovação no processo seletivo. As respostas apresentadas no Gráfico 2, mostram que 50,8\% "não souberam" da aprovação na primeira ou na segunda chamada do PSR 2020. Esta é uma informação importante, pois mostra a necessidade de uma maior divulgação do resultado do processo seletivo. Apesar disso, não se sabe se a falta de conhecimento sobre a aprovação por parte dos candidatos se deu por dificuldade em encontrar o resultado ou falta de interesse em pesquisar. 
Figura 2 - Percentual de candidatos que souberam da aprovação no PSR 2020

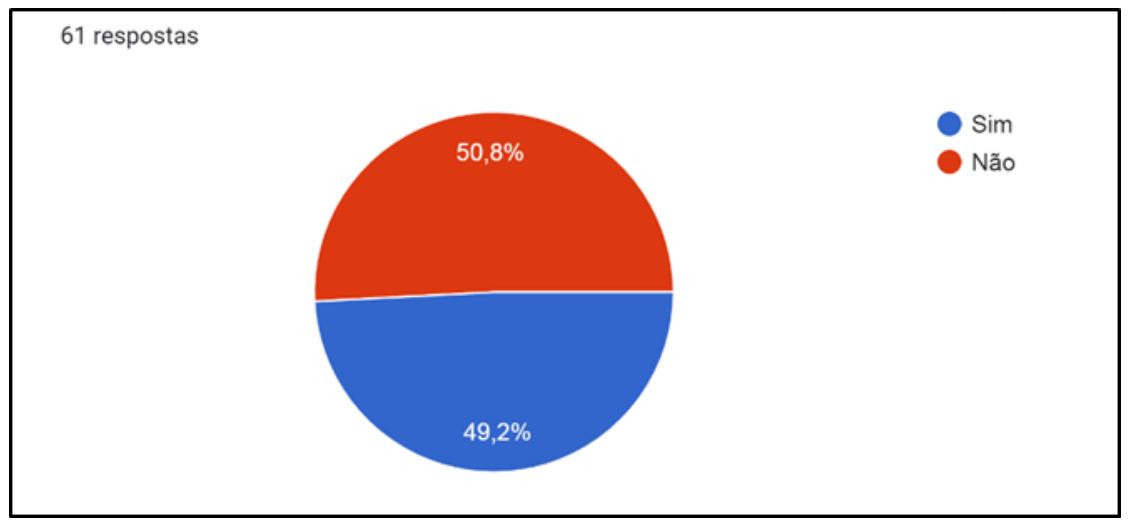

Dentre os candidatos que responderam ao questionário, apenas 30 informaram que souberam da aprovação. Considerando somente esses candidatos, indagou-se sobre o motivo da não realização da matrícula no curso, conforme mostra a Figura 3. 43,3\% dos pesquisados informou que "foi aprovado em outra instituição pública" como principal fator para a não realização da matrícula, ou seja, pode-se presumir que esta instituição seja em outra cidade, ou então na mesma cidade, porém para um curso diferente, e neste caso o curso de engenharia civil não era a primeira opção de escolha deste candidato. Outros $16,7 \%$ dos pesquisados respondeu que "não queria se mudar para Itaituba/PA", ou seja, o fator geográfico neste caso foi decisivo para a escolha do curso e reforça a ideia de que o curso não era a primeira opção de escolha do candidato, porém, concorreu para ver se conseguiria ser aprovado.

Figura 3 - Motivo para não realização da matrícula

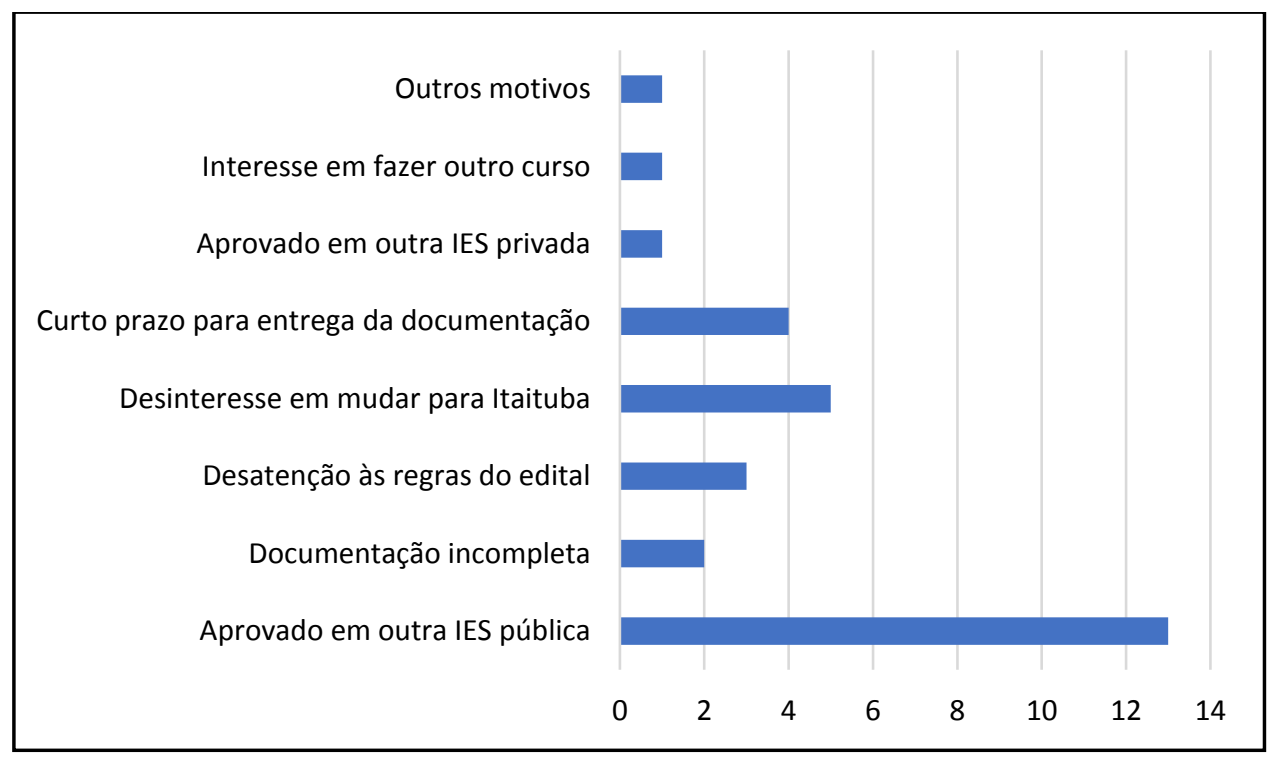

A pesquisa também mostrou que 13,3\% afirmou que o "prazo é muito curto para a entrega da documentação" e que $6,7 \%$ dos candidatos "não estava com a documentação completa", ou seja, foram candidatos que perderam a vaga por não organizar a documentação antes do resultado ser divulgado ou que não tiveram condição de se deslocar até o município de ItaitubaPA para fazer a entrega desses documentos. 
Outro indicador importante para a pesquisa mostra que 10,0\% dos candidatos "não atentou para as regras do edital", neste caso destaca-se a questão das cotas, principalmente as para candidatos provenientes de escolas públicas. Existe uma dificuldade de entendimento de que escolas conveniadas com a Secretaria de Estado de Educação (SEDUC) não são equiparadas a escolas públicas. O edital do PSR é bem claro nesta parte ao destacar, que o candidato classificado para provimento das vagas reservadas aos cotistas devem comprovar, por ocasião da habilitação institucional, que se enquadram nos critérios de grupo (UFOPA, 2019), ou seja, a desatenção ou falta de conhecimento sobre as regras do edital interferem no resultado final do processo seletivo. As respostas menos lembradas, mas que são importantes para a pesquisa, mostraram que 3,3\% dos candidatos informou que "foi aprovado em outra instituição privada" de ensino superior e que 3,3\% "está se preparando para cursar outra área".

\section{CONSIDERAÇÕES FINAIS}

Este estudo objetivou traçar um perfil e verificar o motivo da não realização da matricula por parte dos candidatos aprovados no curso de bacharelado em engenharia civil da Universidade Federal do Oeste do Pará, Campus Itaituba, e contribuir como fonte de dados para criação de ações voltadas à minimização o número de vagas não aproveitadas antes mesmo de iniciar as aulas.

Com base nas informações coletadas na pesquisa, verificou-se que os candidatos que buscam o curso de engenharia civil são, em sua maioria, do gênero masculino e sem formação superior, estão na faixa etária entre 18 e 23 anos, são oriundos de escola pública e que são estudantes ou estão desempregados. A pesquisa também mostrou que se faz necessário uma maior divulgação do resultado do processo seletivo, ampliando as formas de divulgação já utilizadas.

Com relação aos motivos da não realização da matricula na Ufopa, concluiu-se que o fator geográfico quando considerado isoladamente, não é tão decisivo na escolha dos candidatos. Quando pensado o fator geográfico associado a outro fator motivador, como a aprovação em outra instituição pública, a localização interiorana e o acesso mais difícil até a cidade de Itaituba-PA, faz com que se priorize instituições com melhor localização geográfica.

Verificou-se também que o tempo para se chegar ao município de Itaituba-PA, outro fator que pode ser relacionando com a questão geográfica, impossibilitou alguns candidatos a chegarem em tempo ao município para realizar sua matrícula. Neste caso, um item importante que pode ser debatido: considerando a abrangência nacional do processo seletivo regular unificado e as dificuldades de acesso aos municípios mais interioranos, não seria possível estender o prazo para entrega da documentação, dando assim mais chance de esses candidatos se organizarem?

Constatou-se também que existe uma desatenção por parte de alguns dos candidatos, os quais não atentam para as regras previstas em edital e nem providenciam com a devida antecedência a documentação necessária para a habilitação no curso. Com base nestas conclusões podem ser pensadas estratégias no âmbito da Universidade Federal do Oeste do Pará para melhorar a eficiência do processo seletivo regular unificado, minimizando o número de vagas não ocupadas, antes mesmo do início das aulas.

\section{Agradecimentos}

Os autores agradecem à Universidade Federal do Oeste do Pará (UFOPA) e ao Campus Universitário de Itaituba (CITB) pelo apoio e fomento à realização deste e de outros trabalhos. 


\section{REFERÊNCIAS}

ALVES, Marcos Fernando Soares; MANTONAVI, Kátia Luzia. Identificação do perfil dos acadêmicos de engenharia como uma medida de combate à evasão. Revista de Ensino de Engenharia, v. 35, n. 2, p. 26-36, 2016.

ANDIFES - ASSOCIAÇÃO NACIONAL DOS DIRIGENTES DAS INSTITUIÇÕES FEDERAIS DE ENSINO SUPERIOR. V Pesquisa Nacional de Perfil Socioeconômico e Cultural dos (as) Graduandos (as) das IFES - 2018. Uberlândia, MG: [s. n.], 2019. Disponível em: http://www.ufopa.edu.br/media/file/site/ufopa/documentos/2019/3ec756ea4c2150829860af2d 2602f098.pdf. Acesso em: 09 jul. 2020.

ANDRADE, Maria Margarida. Introdução à metodologia do trabalho científico. 10. ed. São Paulo: Atlas, 2018.

COCCO, R. et al. Política de Expansão e Interiorização/Regionalização do Ensino público Superior no Brasil: o caso da UFSM/CESNORS - uma perspectiva a partir do egresso. In: IV CONGRESSO IBERO-AMERICANO DE POLÍTICA E ADMINISTRAÇÃO DA EDUCAÇÃO, Porto, Portugal, 2014.

FLICK, Uwe. Introdução à metodologia da pesquisa. Porto Alegre: Penso, 2013.

SALATA, André. Ensino Superior no Brasil das últimas décadas: redução nas desigualdades de acesso? Tempo Soc., São Paulo, v. 30, n. 2, p. 219-253, 2018.

MARCONI, Marina de Andrade; LAKATOS, Eva Maria. Metodologia científica. 7. ed. São Paulo: Atlas, 2018.

MULLER, Fabiano Hector Lira. A implantação do PARFOR/UFOPA no município de Itaituba/PA: indicadores e resultados. 2019. 102 f. Dissertação (Mestrado em Ensino) Universidade do Vale do Taquari: RS, 2019.

NEVES, Clarissa Eckert Baeta; MARTINS, Carlos Benedito. Ensino Superior no Brasil: uma visão abrangente. In: DWYER, Tom; ZEN, Eduardo Luiz; WELLER, Wivian; SHUGUANG, Jiu; KAIYUAN, Guo (org.). Jovens Universitários em um mundo em transformação: uma pesquisa sino-brasileira. 1. ed. Brasília: IPEA. v. 1. 2016. p. 95-124.

NUNES, E. Ensino universitário, corporação e profissão: paradoxos e dilemas brasileiros. Sociologias, Porto Alegre, ano 9, n. 17, p. 190-215, jan.-jun. 2007.

OLIVEIRA, V. F. et al. Um estudo sobre a expansão da formação em Engenharia no Brasil. Revista de Ensino de Engenharia, Brasília, v. 32, n. 3, p. 37-56, 2013.

PEREIRA, T. I.; SILVA, L. F. S. C. As Políticas Públicas do Ensino Superior no Governo Lula: expansão ou democratização? Revista debates (UFRGS), v. 4, p. 10-31, 2010. 
RECKZIEGEL, Tatiana. O que muda com as novas diretrizes curriculares de Engenharia. 2019. Disponível em: https://desafiosdaeducacao.grupoa.com.br/novas-dcns-de-engenharia/. Acesso em: 13 jul. 2020.

SILVA FILHO, Roberto Leal Lobo et al. A evasão no ensino superior brasileiro. Cadernos de Pesquisa, São Paulo, v. 37, n. 132, p. 641-659, 2007.

UFOPA - UNIVERSIDADE FEDERAL DO OESTE DO PARÁ. Edital No 57/2019. CPPS/UFOPA, de 02 de dezembro de 2019. Processo Seletivo Regular Unificado 2020 (PSR/UFOPA 2020). 2019. Disponível http://www.ufopa.edu.br/media/file/site/proen/documentos/2019/76e50e12f43fe482ca7c6c67 641d9df5.pdf. Acesso em: 13 jul. 2020.

Plano de Desenvolvimento Institucional da Ufopa 2019-2023. 2020. Disponível em: <http://www.ufopa.edu.br/media/file/site/proplan/documentos/2020/766ea1d5a36f6bde3acdc 4b46199218e.pdf>. Acesso em: 09 jul. 2020.

\title{
ANALYSIS OF THE FACTORS THAT CONTRIBUTE TO THE LOW COMPARISON INDEX IN THE QUALIFICATION FOR THE CIVIL ENGINEERING COURSE AT A UNIVERSITY IN AMAZON'S INTERIOR
}

\begin{abstract}
This study seeks to outline a profile and verify the reason for the failure of enrollment by some candidates approved in the course of civil engineering at Federal University of Western Para - Campus Itaituba and to contribute as a data source for the creation of actions aimed at minimizing the number of unused places, even before classes start. It is characterized as a quantitative and descriptive research and for data collection, an online questionnaire was sent to approved candidates, but who did not enroll in the course. It was concluded that the candidate are mostly male, aged between 18 and 23 years old, coming from public school, and who are students or unemployed. It was also found that the geographic factor, when considered in isolation, is not the main motivating factor for non-enrollment, but when associated with another factor, such as approval in another public institution, this more difficult access to the city of Itaituba, prioritizes institutions with a better geographical location. The geographic factor also influenced the candidates to drop out due to the time to it took to get to the city of register. It was also found that there is a lack of attention on part of some candidates who do not pay attention to the rules foreseen in the notice and do not provide the necessary documentation for the qualification in the curse with due advance.
\end{abstract}

Keywords: Registration. Civil Engineering. Ufopa. Campus Itaituba. 